UNIVERSIDADE ESTADUAL DE FEIRA DE SANTANA

Autorizada pelo Decreto Federal $n^{\circ} 77.496$ de $27 / 04 / 76$

PRÓ-REITORIA DE PESQUISA E PÓS-GRADUAÇÃO

PPPG

COORDENAÇÃO DE INICIAÇÃO CIENTÍFICA

XXIII SEMINÁRIO DE INICIACÃO CIENTÍFICA DA UEFS

SEMANA NACIONAL DE CIENTÍFICA E TECNOLÓGICA - 2019

\title{
INSERÇÃO DA BAHIA NAS CADEIAS REGIONAIS DE VALOR: UMA ANÁLISE SETORIAL
}

\author{
Matheus Souza Dantasi'; Rosembergue Valverde ${ }^{2}$ \\ 1. Bolsista PIBIC/CNPq, Graduando em Ciências Econômicas, Universidade Estadual de Feira de Santana, e-mail: \\ msdantas@uefs.br \\ 2. Orientador, Departamento de Ciências Sociais Aplicadas, Universidade Estadual de Feira de Santana, e-mail: \\ rosembuerguevalverde@uefs.br
}

PALAVRAS-CHAVE: Crescimento Econômico. Economia Baiana. Cadeias Regionais de Valor.

\section{INTRODUÇÃO}

Este trabalho teve por objetivo analisar a inserção da economia baiana nas cadeias regionais de valor, com base nas relações de comércio inter-regional descritas pela Matriz Interestadual de Insumo-Produto para Brasil - 2017. Seguindo a metodologia proposta por Robert Koopman, Zhi Wang e Shang-Jin Wei (2014), este estudo avalia os indicadores que refletem a participação, a posição e o grau de especialização da economia baiana na geração do valor adicionado para a produção nacional. Os resultados sugerem que a Bahia é exportadora de produtos primários de baixo valor agregado, sendo assim, muito dependente de insumos e produtos importados de outros estados para atender, respectivamente às suas necessidades de demanda final e consumo intermediário industrial. Depreende-se também que o conteúdo de produtos importados oriundos dos demais estados no valor das exportações baianas para seus parceiros comerciais nacionais é significativamente elevado. Em síntese, a forma de integração da economia baiana nas cadeias regionais de valor torna o crescimento econômico do estado fortemente dependente do desempenho da economia nacional e da economia internacional.

Portanto, os objetivos específicos deste trabalho são três. O primeiro é decompor as exportações brutas por setor da economia baiana em seus componentes do valor adicionado. $\mathrm{O}$ 
segundo e terceiro consistem em avaliar a participação e a posição dos setores que concentram a maior participação da economia baiana na cadeia nacional de valor.

\section{METODOLOGIA}

A base de dados utilizada como referência foi a Matriz Interestadual de Insumo-Produto para o Brasil, produzida por Eduardo Haddad, Carlos Alberto Gonçalves Junior e Thiago Nascimento (2017), a qual estima as relações estabelecidas entre os 26 Estados mais o Distrito Federal para 68 setores na cadeia produtiva de geração de valor, e divide a produção em demanda final ( dividida em consumo das famílias, gastos do governo, investimento, variação no estoque e exportações) e consumo intermediário. Utilizou-se do software MATLAB (MATrix LABoratory) para análise dos dados e construção dos indicadores utilizados neste trabalho.

A fim de identificar a formação do valor adicionado, foi utilizada a metodologia desenvolvida por Robert Koopman, Zhi Wang e Shang-Jin Wei (2014). Sendo esta dividida em dois blocos: valor adicionado doméstico e valor adicionado externo. Estes dois blocos, por sua vez, foram repartidos em 9 termos, com o objetivo de fragmentar as exportações e identificar a formação do valor adicionado interno e estrangeiro destinados para à demanda final, ao consumo intermediário e para exportar para os demais estados da Federação.

Por fim, foram utilizados dois indicadores sintéticos para analisar a participação na formação do valor adicionado e a posição de cada setor nas cadeias regionais de valor. A participação pode ser medida para frente (forward) e para trás (backward). A primeira medindo a participação do valor adicionado doméstico nas exportações para terceiros. A segunda, a participação do conteúdo externo nas exportações. O indicador de posição, por sua vez, avalia como o setor está posicionado nas cadeias regionais de valor. Se está posicionado como exportador de produtos com alto valor agregado ou produtos de baixo valor agregado. Os efeitos do padrão de especialização vertical 


\section{RESULTADOS}

Conforme procedimentos metodológicos descritos na seção anterior, essa seção examina a inserção da economia baiana nas cadeias regionais de valor. Inicialmente, as exportações de cada setor da Bahia podem ser divididas em dois grupos: DVA - domestic value added e FVA - foreign value-added.

Gráfico 1 - Participação do Valor adicionado doméstico

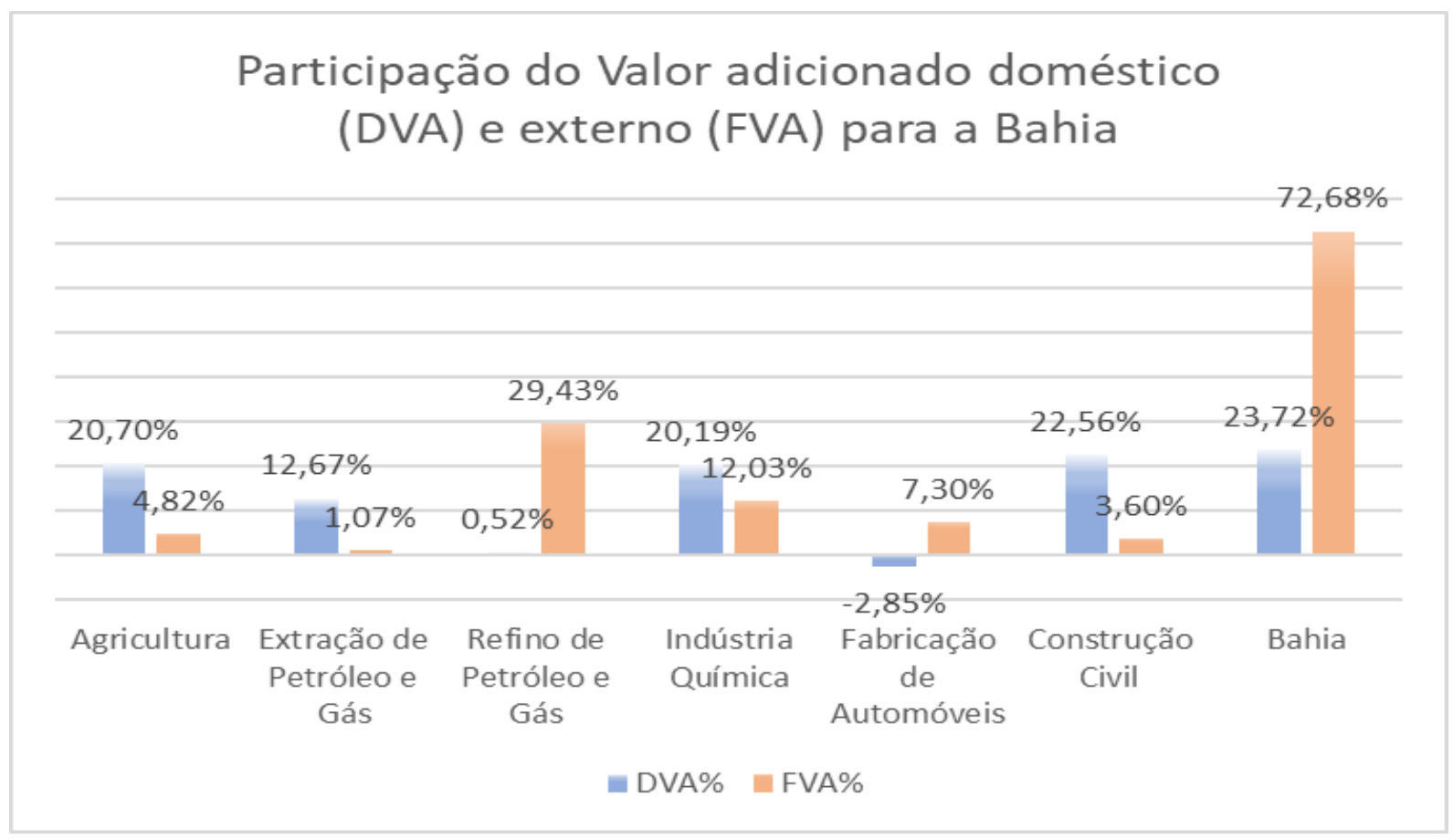

Fonte: Elaborado pelo autor (2019).

Ao analisar a participação do valor adicionado doméstico às exportações de cada setor (Gráfico 01), pode-se perceber facilmente que os setores de construção civil, agricultura e indústria química, cada um, compõem as suas exportações de um quinto em valor agregado doméstico. No entanto, quando observada a composição do DVA de cada setor representado no gráfico 01 , é revelada a heterogeneidade na formação do valor agregado genuinamente doméstico nas exportações brutas do Estado. Por sua vez, o setor de fabricação de automóveis, apesar da sua elevada participação no volume de exportações do estado, revela a fragilidade do seu modo de inserção nas cadeias regionais de valor.

A posição da Bahia nas cadeias de valor pode ser verificada ao se decompor o DVA e o FVA de cada setor em seus elementos constitutivos. Primeiro, avalia-se a decomposição do 
DVA em dois subgrupos: DVA_1 e FVA_2, conteúdo doméstico e externo das exportações respectivamente. Em seguida, o primeiro termo desse subgrupo (DVA_1) é decomposto em três outros subgrupos, para as exportações com destino a demanda final (DVA_1.1 e DVA_2.1); ao consumo intermediário industrial (DVA_1.2 e DVA_2.2); e para exportações de estados terceiros (DVA_1.3 e DVA_2.3). Por fim, decompõe-se do FVA nos seus três termos constitutivos que correspondem aos fluxos comerciais de comércio inter-regional: importações, agregação de valor e exportações para a demanda final (FVA_1); importações, agregação de valor e exportações para a demanda intermediária industrial (FVA_2); e importação, agregação de valor e exportação de terceiros (FVA_3).

Tabela 1- Decomposição dos termos de KOOPMAN entre os setores.

\begin{tabular}{ccccccc}
$\begin{array}{c}\text { TERMOS } \\
\text { de } \\
\text { Koopman }\end{array}$ & Agricultura & $\begin{array}{c}\text { Extração de } \\
\text { Petróleo e Gás }\end{array}$ & $\begin{array}{c}\text { Refino de } \\
\text { Petróleo e Gás }\end{array}$ & $\begin{array}{c}\text { Indústria } \\
\text { Química }\end{array}$ & $\begin{array}{c}\text { Fabricação de } \\
\text { Automóveis }\end{array}$ & $\begin{array}{c}\text { Construção } \\
\text { Civil }\end{array}$ \\
\hline DVA_1.1 & $0,80 \%$ & $2,22 \%$ & $-0,57 \%$ & $0,43 \%$ & $-6,78 \%$ & $16,86 \%$ \\
DVA_1.2 & $12,78 \%$ & $13,00 \%$ & $-13,35 \%$ & $8,89 \%$ & $-0,27 \%$ & $4,01 \%$ \\
DVA_1.3 & $6,64 \%$ & $6,71 \%$ & $-6,78 \%$ & $4,96 \%$ & $-0,27 \%$ & $1,55 \%$ \\
DVA_2.1 & $0,26 \%$ & $0,26 \%$ & $-0,27 \%$ & $0,19 \%$ & $-0,01 \%$ & $0,06 \%$ \\
DVA_2.2 & $0,76 \%$ & $0,68 \%$ & $-0,67 \%$ & $0,51 \%$ & $-0,01 \%$ & $0,12 \%$ \\
DVA_2.3 & $-0,54 \%$ & $-10,21 \%$ & $22,16 \%$ & $5,21 \%$ & $4,49 \%$ & $-0,04 \%$ \\
FVA_1.1 & $0 \%$ & $0,17 \%$ & $0,02 \%$ & $0,07 \%$ & $6,80 \%$ & $3,00 \%$ \\
FVA_1.2 & $0 \%$ & $0,06 \%$ & $4,65 \%$ & $0,97 \%$ & $0,17 \%$ & $0,33 \%$ \\
FVA_1.3 & $4 \%$ & $0,84 \%$ & $24,76 \%$ & $10,98 \%$ & $0,34 \%$ & $0,27 \%$ \\
\hline FOH.: & & & & &
\end{tabular}

Fonte: Elaborado pelo autor (2019).

Da Tabela 01 pode-se perceber que o setor que mais agrega valor ao que é exportado para a demanda final (DVA_1.1) é a construção civil, representando 16,86\% do total do valor adicionado doméstico, aquele que mais produz direcionado ao consumo final. Para os demais cinco setores, que representam a maior parte das exportações baianas, a exportação para a demanda final (DVA_1.1) é extremamente discreta. Quando analisado o DVA_2.1, o que o setor exporta, importa, e, posteriormente, exportar para a demanda final, o desempenho não ultrapassa $0,26 \%$ para nenhum setor listado. Pode-se concluir a elevada concentração de bens intermediários para o consumo intermediário. A agricultura e a extração de petróleo e gás estão entre os setores que contém maior conteúdo doméstico nas exportações. DVA e FVA, respectivamente, agricultura $(12,78 \% ; 6,64 \%)$, e extração de petróleo e gás $(13 \% ; 6,71 \%)$. São setores primários, extraem seus produtos direto da natureza, em geral, exportados para 
utilização como bens intermediários no processo produtivo. Esses setores, localizados no início da cadeia produtiva, possuem baixa escala para diferenciação.

Apesar de possibilitar diversificar a atuação econômica e gerar novas oportunidades para o Estado, setores fornecedores de commodities possuem baixa capacidade de promover transportações de patamar para a economia da Bahia, sendo os efeitos gerados pela sua atividade econômica limitados e pontuais geograficamente (GUERRA e GONZALES, 1996). Assim, pode ser percebida a baixa capilaridade que a agricultura e a extração de petróleo têm na inserção nas cadeias regionais de valor.

No que se refere ao valor adicionado externo, os setores que contém maior parcela do conteúdo externo às suas exportações são refino de petróleo $(24,76 \%)$ e indústria química $(10,98 \%)$. A participação elevada do conteúdo externo revela que os setores muito pouco agregam valor ao produto, na maioria das vezes, contribui com processos produtivos pontuais, movimentando apenas os fluxos de renda, mas a riqueza gerada é não é internalizada.

\section{CONSIDERAÇÕES FINAIS}

O presente artigo buscou analisar a inserção dos setores que representam a maior parcela do volume de exportações da economia baiana nas cadeias regionais de valor. Como resultado, observou-se que o déficit comercial para a Bahia é mais expressivo quando analisada a formação do valor adicionado doméstico e estrangeiro que quando observada simplesmente o saldo da balança comercial. Além do mais, percebe-se também a elevada dependência de insumos intermediários para compor a produção setorial. Cabe considerar que uma elevada participação de bens intermediários não é suficiente para concluir sobre a fragilidade do setor.

No entanto, a análise da decomposição das exportações para as cadeias regionais de valor revela que as exportações setoriais da agricultura e da extração de petróleo muito pouco se destinam para atender à demanda final, ou seja, a maior participação da sua produção é como bens intermediários. Esses setores refletem a elevada dependência da economia local à dinâmica da economia nacional. A elevada presença do conteúdo externo dos setores refino de petróleo e indústria química indicam que a grande parcela da receita obtida na participação do comércio regional é destinada para remunerar os fatores de produção externos. 
Os setores agricultura e extração de petróleo e gás, apesar de estarem posicionados como exportadores de bens intermediários, reforçando conclusões já citadas, contribuem para as cadeias regionais de valor com bens de baixa capacidade de diferenciação e elevada vulnerabilidade de fatores externos.

\section{REFERÊNCIAS}

HADDAD, Eduardo, GONÇALVES JUNIOR, Carlos Alberto, e NASCIMENTO, Thiago (2017). Matriz Interestadual de Insumo-Produto para o Brasil: Uma Aplicação do Método IIOAS. Revista Brasileira de Estudos Regionais e Urbanos (RBERU), v. 11,n. 4, pp. 424-446.

KOOPMAN, Robert.; WANG Zhi.; WEI, Shang-Jin (2014). Tracing value-added and double counting in gross exports. The American Economic Review, v. 104, n. 2, p.459-94.

GUERRA, Oswaldo e GONZALES, Paulo (1996). Evolução Recente e Perspectivas Para a Economia Baiana. Revista econômica do Nordeste, v. 1, p. 35. 